\title{
A AVALIAÇÃO COMO SINONÍMIA E REFLEXÃO
}

Afrânio da Silva Garcia (UERJ-FFP)

Resumo: A etimologia dos termos sinônimos ou quase sinônimos referentes à avaliação da aprendizagem pode ser dividida em três grupos básicos: palavras que dizem respeito à observação, palavras que dizem respeito à sondagem ou teste e palavras que dizem respeito à comprovação. Esses grupos são de grande importância para o professor na hora de decidir qual o tipo de avaliação mais adequado para cada classe, de acordo com os objetivos que se pretende alcançar, o públicoalvo, o auditório, o grau de certeza que se almeja atingir, a necessidade documental a que se está sujeito, o comprometimento do aluno etc. Uma vez estabelecidas as características da turma, por meio dos critérios estabelecidos e das implicações de cada modalidade de verificação de aprendizagem, fica mais fácil optar pela avaliação mais apropriada aos estudantes, em termos de aproximação à realidade e de eficácia.

Palavras-chave: Avaliação; Etimologia; Sinonímia; Eficácia.

Abstract: The etymology of the synonymous terms or almost synonymous terms concerning to learning can be divided into three basic groups: words related to observation, words related to probing, or testing and words related to attestation, or evidence. These groups are of great importance to the teachers when they are deciding what type of evaluation should be more appropriate for each class, according to the objectives to be achieved, the target audience, the auditorium, the degree of certainty that one aims to achieve, the documentation needs to which one is subject, the students' engagement etc. Once established the class characteristics, through the established criteria and the implications of each modality of learning verification it becomes easier to choose the most appropriate evaluation to students in terms of approximation to reality and effectiveness.

Key-words: Evaluation; Etymology; Synonymy; Effectiveness. 


\section{INTRODUÇÃO}

Um dos grandes problemas da prática pedagógica, principalmente no ensino de português, é decidir sobre que tipo de avaliação deverá ser empregado para verificação da aprendizagem: provas, trabalhos práticos, projetos, monografias, apresentações orais etc.

Um auxílio inesperado com que o professor de português pode contar para definir qual a melhor forma de avaliação do rendimento de seus alunos reside na etimologia dos sinônimos empregados para designar as formas de avaliação disponíveis: exame, teste, prova, avaliação, verificação etc.

Mergulhando na origem desses termos, podemos elaborar parâmetros úteis e definidos para nossas avaliações, de acordo com os objetivos que queremos alcançar, o públicoalvo, o auditório de nossas aulas ou palestras, o grau de certeza que queremos atingir, a necessidade documental a que estamos sujeitos, o maior ou menor nível de honestidade do alunado etc.

Uma vez cientes do que cada modalidade de avaliação implica, estaremos bem mais à vontade para a realização de nossas verificações de aprendizagem, pois elas tenderão a se aproximar cada vez mais da realidade de seu públicoalvo e da eficácia. 


\section{A SINONÍMIA CONCERNENTE À AVALIAÇÃO}

A sinonímia relacionada à avaliação que se pode encontrar nos dicionários e compêndios de educação compreende os seguintes grupos de palavras:

1. Palavras que dizem respeito à observação, como: apresentação, ato de esquadrinhar ou de perscrutar, demonstração, exame, exame crítico, exame cuidadoso, examinação, exibição, investigação, observação, observação minuciosa, verificação, verificação de aprendizagem.

2. Palavras que dizem respeito à sondagem ou teste, como: análise, apuração, avaliação, avaliação crítica, averiguação sistemática, averiguação, escrutínio, experiência, experimentação, experimento, pesquisa, sondagem, teste.

3. Palavras que dizem respeito à comprovação, como: arguição, certame, certificação, competição, comprovação, concurso, prova, prova oral, questionário, sabatina.

4. Palavras que dizem respeito à tarefa, como: dissertação, ensaio, estudo, estudo pormenorizado, monografia, tarefa, tarefa a cumprir, trabalho, trabalho escolar, tese.

Optamos por selecionar as palavras que dizem respeito à tarefa no grupo relacionado à comprovação, uma vez que tais tarefas são voltadas para a verificação do aprendizado ou da aquisição de uma determinada habilidade. 
O estudo etimológico dessas palavras revelou que a maioria mantém no português atual quase a mesma significação de sua origem. São dignas de nota apenas as palavras exame e sabatina. Proveniente de enxame, por associação entre a quantidade de questões ou pensamentos e um enxame de abelhas surgiu exame; e sabatina, originalmente significava uma revisão realizada aos sábados.

\section{A AVALIAÇÃO COMO OBSERVAÇÃO}

Uma das perspectivas que podemos adotar com relação à avaliação é considerá-la um tipo especial de observação com que verificaremos como o aprendiz está incorporando em sua consciência e em sua vida os saberes e as técnicas que Ihes foram ensinados.

Esse tipo de avaliação leva em conta as diferenças individuais na medida em que ele não cobra do estudante uma meta a ser alcançada, apenas verifica os progressos e as dificuldades que o aluno demonstra em seu processo de aquisição do conhecimento. Podemos dizer que ele é muito mais oneroso para o docente do que para o discente, uma vez que a função primordial da observação é evidenciar se os objetivos estabelecidos estão sendo alcançados.

A avaliação como observação é ideal para os cursos de alfabetização e para a primeira série do ensino 
fundamental, visto que a criança sendo (quase que inevitavelmente) submetida ao estresse de se ver separada da mãe (ou dos pais) ficaria ainda mais ressentida se tivesse que ser submetida a provas e passar por comparações; possivelmente ficaria ainda mais desestimulada. Os clubes e academias sabem disso muito bem, tanto assim que os cursos de natação para crianças pequenas dão medalhas para todos aqueles que efetivamente se esforçam, não importando o seu desempenho. Por outro lado, o processo de ensino-aprendizagem de crianças pequenas não é, de forma alguma, uniforme e tampouco linear, em muitos casos. Algumas crianças aprendem literalmente brincando aquilo que outras crianças têm de se esforçar muito para aprender; algumas crianças evoluem nas etapas da alfabetização (pré-silábica, silábica etc.) de forma progressiva e contínua, enquanto outras ficam estacionadas numa determinada etapa por algum tempo, ou até regridem para uma etapa anterior antes de tornarem a progredir. Imagine o grau de constrangimento e frustração se elas fossem submetidas a exames para comprovar seu rendimento e ficasse provado que elas estavam "piores" (melhor dizendo, tinham regredido) no seu aprendizado.

Outro tipo de ensino em que a avaliação como observação é aconselhável é o ensino de habilidades 
artísticas, culturais ou esportivas. Embora todos já tenham sonhado em ser um atleta ou artista de sucesso, o talento das pessoas varia enormemente; no entanto, é uma das funções mais importantes da educação facilitar o acesso de todos, principalmente das crianças, às artes, à cultura e ao esporte. Afinal, como dizia Dewey": "A educação é um processo social, é desenvolvimento. Não é a preparação para a vida, é a própria vida." A alegria é parte da vida, e a apreciação ou execução de uma obra de arte, a fruição da cultura, o deleite do esporte fazem parte dessa vida melhor, que é o objetivo mesmo da educação; ora, haveria maior desmancha-prazeres do que um mestre que submetesse um aluno a uma prova de rock'n'roll, ou de impressionismo, ou de "pelada"? Além disso, embora se possa (e deva) estudar as jogadas de Pelé, os acordes de Pixinguinha, as cores de Van Gogh, a essência da qualidade dessas pessoas não pode ser aprendida, pode-se apenas tentar estimular o aluno a apreciá-las, instrumentalizando-o com saberes e técnicas que o levarão a ser tão bom ou melhor do que esses ídolos, mas nunca igual a eles!

Em suma, podemos dizer que a avaliação como observação constituiria a melhor opção em relação àqueles saberes cujo aprendizado é extremamente variável, seja porque o $1 \mathrm{Cf} .<$ https://sites.google.com/site/filosofiapopular/filosofos/john-dewey > Acesso em 10.Jul.2105. 
sujeito do aprendizado apresenta diferenças individuais que não podem nem devem ser relevadas, seja porque o objeto do aprendizado é, por sua própria natureza, difuso e em evolução constante.

\section{A AVALIAÇÃO COMO TESTE}

O renomado educador Pedro Demo defende o teste como o melhor tipo de avaliação, dizendo implicitamente que a educação deve ser submetida ao mesmo tipo de avaliação que fazemos com todas as outras coisas: "testar para ver se funciona". É inegável a sabedoria desta comparação que critica uma deficiência presente em muitos tipos de provas ou exames: a desvinculação entre o que é cobrado na avaliação e aquilo que realmente tem importância e utilidade, em termos práticos (cf. Saber pensar², 2008. p. 47-53; p. 123-130).

Outro estudioso, Gustavo Krause (2002, p. 221-224) radicaliza sua crítica ao modelo de prova propondo a adoção da "cola", rebatizada eufemisticamente como consulta, em todas as avaliações, partindo do argumento (altamente questionável) de que o aluno cola porque os métodos de avaliação são absurdos e perversos. Sem insistir muito no termo, ele também aponta como a melhor opção a avaliação do tipo teste.

$2 \mathrm{Cf}$. http://www.observatoriodaeducacaodorn.org.br/?p=ent\&cod=358 Acesso em 10.Jul.2015. 
De maneira geral, Demo e Krause estão certíssimos: sempre que tivermos uma turma ou estudantes com um mínimo de engajamento e nos for dado um mínimo de liberdade de cátedra. Em conformidade com Lei 9394/963 (LDB), em seu Art. 3으, “O ensino será ministrado com base nos seguintes princípios":

I - igualdade de condições para o acesso e permanência na escola;

II - liberdade de aprender, ensinar, pesquisar e divulgar a cultura, o pensamento, a arte e o saber;

III - pluralismo de ideias e de concepções pedagógicas (...)

Trata-se de importantíssima noção pedagógica que consiste a liberdade de um mestre ou professor proceder aos ensinamentos da maneira que ele achar mais produtiva e eficaz; portanto podemos/devemos fazer experiências, sondagens, testes e similares conforme o desenvolvimento do processo de ensino-aprendizagem, para "ver se está funcionando", ou seja, ver se nosso aluno está aprendendo e apreendendo, se ele está de fato incorporando os saberes, técnicas e habilidades que estamos buscando ensinar.

Essa é sem dúvida a melhor forma de avaliar, mas também a que exige maior esforço dos dois agentes: (1) o aluno 
terá realmente de se integrar ao estudo e à aprendizagem; (2) o professor terá de participar também das avaliações e partilhar os progressos e dificuldades de seus alunos. Esse processo exige um exercício constante e permanente de retroalimentação (feedback), com os alunos e os professores se comunicando continuamente. Enfim, dessa forma o curso será muito mais ativo e dinâmico, apesar de extenuante, pois algumas características (tradicionalmente associadas à educação) como a distância entre professores e alunos (nos dois sentidos) e a "bagunça" terão que ser drasticamente abandonadas.

Com a salutar adoção da avaliação como teste, os meios de avaliação se ampliarão muito. Além do teste escrito tradicional, deve haver provas práticas, pesquisas na internet e nas bibliotecas, saídas em grupo, elaboração de material instrucional em multimídia, atividades extracurriculares, estágios etc. A pesquisa, com estatísticas e resultados reais, deverá ser feita. No âmbito do ensino de português, uma revolução vem sendo feita a partir do estudo da Norma Urbana Culta, desmitificando várias crenças arraigadas nos compêndios de português. A Gramática do Português Falado, do professor Ataliba Castilho, veio sacudir os alicerces dos estudos do vernáculo. 
O próprio papel do professor ${ }^{4}$ também se modifica quando ele adota a avaliação como teste. 0 docente passa a ser o coordenador de uma equipe de pesquisa, o orientador de um grupo de estudos, o editor de artigos produzidos em sala de aula ou sobre o assunto estudado, o professor-responsável (ou supervisor) pela participação de seus discípulos em eventos acadêmicos ou feiras científicas; tudo muito vivo, muito instigante e muito, muito trabalhoso.

A avaliação como teste, mesmo que o professor só tenha condições de aplicar testes escritos, ainda é a melhor opção. Infelizmente, o aluno brasileiro está acostumado a uma educação que exige muito pouco dele, de tal forma que o professor chega a se assombrar quando encontra um aluno participativo. Mas o professor deve insistir e submeter seus alunos a testes e sondagens, fazê-los participar de experiências e pesquisas; enfim, fazer avaliações que analisem de maneira objetiva o desenvolvimento de seus alunos.

\footnotetext{
4 A literatura especializada vem chamando o professor que adota esta postura de professor profissional, mas esta nomenclatura não é correta. Por um lado, os professores tradicionais, em que pese terem adotado, de maneira geral, a avaliação como comprovação, muitas vezes foram profissionais brilhantes, que nos ensinaram muito (como meus inesquecíveis professores Dalva, do Ensino Fundamental, Ronaldo, de História, Tanajura, de Português, e Jacira, de Inglês). Por outro lado, muitos usam esta nomenclatura com um sentido mercantilista, chamando de professores profissionais aqueles que são, de uma certa forma, explorados, tendo de trabalhar dentro e fora da escola, sem uma contraparte financeira que justifique seu esforço extra.
} 


\section{A AVALIAÇÃO COMO COMPROVAÇÃO}

A avaliação como comprovação é, sem dúvida, a melhor opção em situações de conflito ou descaso com a educação, o que é tão frequente no Brasil, onde mais parece que a escola existe como uma desculpa para políticos corruptos roubarem somas astronômicas que são destinadas à educação, mas que ninguém sabe onde vão parar, visto o estado de abandono em que nossas instituições educacionais vivem, sem bibliotecas, com prédios caindo aos pedaços e móveis quebrados, professores mal pagos e, o que é pior, sem ter sequer papel higiênico e sabonete nos banheiros.

Nesse contexto, qualquer professor com um mínimo de responsabilidade tem de optar por um tipo de avaliação que prove e comprove que seus alunos adquiriram um mínimo de conhecimento que os tornou, ao menos razoavelmente, preparados naquela área de saber ou naquela técnica ou habilidade ensinada: em suma, a famigerada prova.

Professores universitários estão cansados de (imbuídos das melhores intenções) proporem excelentes trabalhos de pesquisa, envolvendo livros e sites de qualidade, para receberem trabalhos de uma ou duas páginas, feitas de qualquer jeito, ou trabalhos mais extensos, inteiramente roubados da internet. Em cursos de especialização, mestrado 
e doutorado, constata-se a prática comum de encomenda/ compra de monografia, dissertação ou tese, pois há uma centena de empresas que oferecem esse serviço. A prática de compra de trabalhos demonstra o grau de desrespeito e de irresponsabilidade com que o estudante brasileiro vê a educação atualmente, salvo raras exceções.

No ensino fundamental e secundário, e também nos cursos de graduação, a "cola, sombra da escola" (Krause, 2002) ocorre na maior desfaçatez, a ponto de vários professores receberem trabalhos absolutamente idênticos. Nas instituições particulares, o número de conflitos e processos de plágio ganhou proporções que levaram algumas instituições a optar por aplicar prova sem a presença do professor, apenas com um ou mais fiscais, encarregados unicamente de coibir a "cola". Para tanto, adotam como padrão a prova de múltipla escolha, pois esta minimiza a margem de duplas interpretações, argumento frequente nos processos jurídicos referidos.

Neste contexto de desonestidade, descaso e corrupção, só a avaliação como prova é capaz de produzir um documento minimamente confiável contra abusos e delitos. Inclusive porque os diplomas e certificados de conclusão de cursos servem para atestar a competência para alguém exercer um 
ofício ou uma profissão. Como podemos em sã consciência dar um diploma de professor de português a quem não tem domínio em nível técnico desta língua/disciplina? O mesmo seria conferir um certificado de operador de raios- $X$ a quem não sabe operar esse tipo de máquina? O incêndio da Boate Kiss está aí para comprovar o perigo da certificação/ diplomação sem critério de qualidade.

O professor que lida com alunos desonestos ou negligentes deve aplicar somente avaliações de comprovação: provas, exercícios feitos em sala de aula, arguições, e tarefas, muitas tarefas, sempre realizadas em sala de aula, para estimular os alunos negligentes a produzirem e, ao mesmo tempo, retribuir alunos interessados e diligentes (que sempre há), os quais merecem receber do professor um tratamento que lhes ateste a competência como resultado de empenho.

Em situações muito especiais, pode-se até fazer uma prova de múltipla escolha, contanto que se aumente a complexidade das opções. Na minha prática pedagógica, como professor de português de instituições privadas, já apliquei provas de sintaxe em que pedia para o aluno relacionar uma coluna com dez orações sublinhadas a outra coluna, com vinte e dois tipos de oração do português. 
Provavelmente alguém colou, mas o trabalho de correlacionar dez orações a vinte e dois tipos deve ter dificultado bastante esse tipo de fraude.

Isso é bom? Não, mas é o que temos para hoje. E o professor tem que ensinar no mundo real, na escola real, para o aluno real, e tentar fazer o melhor que pode. Somente a avaliação como comprovação, a prova, pode garantir um mínimo de credibilidade na aferição dos resultados. Comprova-se isso com fatos como: (a) proliferação de faculdades particulares com alto índice de aprovação (e com nota alta!); perpetração da aprovação automática e instituição do ENEM - Exame Nacional do Ensino Médio - como critério único para ingresso nas universidades. Em contraponto, entidades de classe, como a Ordem dos Advogados do Brasil (OAB) e o Sindicato dos Médicos, insistem em realizar suas próprias avaliações para exigir/garantir um mínimo de competência dos advogados e médicos, respectivamente.

\section{CONCLUSÃO}

Como vimos anteriormente, embora a avaliação como teste seja a mais abrangente e eficaz, ela não pode ser usada indiscriminadamente, pois seu emprego depende de condições específicas tanto do aluno, que deve ser empenhado e participante, quanto do professor, que deve estar disposto 
a se envolver pessoalmente na avaliação de seus alunos, bem como orientá-los em suas produções e pesquisas.

Casos há em que a avaliação como observação é a mais indicada, principalmente com crianças pequenas e com habilidades que variam de pessoa para pessoa.

Em situações especiais, no entanto, o mais aconselhável é a avaliação como comprovação (a prova), que não dá margem a dúvidas e, além de dificultar a fraude, gera um documento que talvez seja necessário no futuro.

Essas são algumas questões suscitadas pela sinonímia no campo léxico da avaliação, as quais podem, além do discernimento docente e de sua liberdade de cátedra, servir de orientação na escolha do melhor tipo de avaliação para suas turmas.

\section{REFERÊNCIAS}

KRAUSE, G. Bernardo. (2007). Educação pelo argumento. Rio de Janeiro: Rocco.

DEMO, Pedro. (2002). Saber pensar. São Paulo: Cortez: Instituto Paulo Freire.

Afrânio da Silva Garcia concluiu o Doutorado em Letras (Letras Vernáculas) pela Universidade Federal do Rio de Janeiro em 1996; também na Universidade Federal do Rio de Janeiro concluiu seu Mestrado em Letras (Letras Vernáculas) em 1988 e se graduou em Letras (Português-Inglês) em 1980. Atualmente é Professor Adjunto da Universidade do Estado do Rio de Janeiro, onde atua na graduação e na especialização. Realiza pesquisas na área de Letras, com ênfase 
em Semântica, Língua Portuguesa, Estilística, Interpretação, Retórica, Semiologia, Sintaxe, Figuras de Linguagem e Ensino, Publicou 72 artigos em periódicos especializados e 43 trabalhos em anais de eventos. Possui 9 livros publicados, dentre os quais destacam-se: Estudos universitários em semântica (2a edição rev. e atual.). Rio de Janeiro: Edição do Autor, 2006, 154 p. Ensaios: linguística e estilística (3a edição). Rio de Janeiro: Edição do autor, 2008, p.100 p.; Antes da espada do tempo (2a edição). Rio de Janeiro: Edição do autor, 2008, 95 p.; Amarantes e Depois no 5 Agosto a Dezembro de 2005 (Diretor). São Gonçalo: UERJ-São Gonçalo, 2005. 88 p.; Amarantes e Depois no 4 - Agosto a Dezembro de 2005 (Diretor). São Gonçalo: UERJ-São Gonçalo, 2005. 90 p. É membro do grupo de pesquisa SELEPROT e da Academia Brasileira de Filologia. Participou de 43 eventos no Brasil e no exterior. Recebeu 3 prêmios ou títulos, inclusive o Prêmio Francisco Alves de 1993 (melhor livro sobre língua portuguesa) da Academia Brasileira de Letras - ABL. Organizou 12 eventos, sendo um de caráter internacional. Participou recentemente de oito eventos internacionais, na China, em Portugal, na Itália, na França e nos Estados Unidos. Recentemente, teve dois trabalhos publicados nos Estados Unidos. Seu endereço de e-mail é afraniogarcia@gmail.com. Endereço para acessar CV Lattes: http://lattes.cnpq.br/3408824183237935 